\title{
REVERSIBLE HYDROGEN SORPTION IN THE COMPOSITE MADE OF MAGNESIUM BOROHYDRIDE AND SILICA
}

\section{AEROGEL}

Miriam Rueda ${ }^{\mathrm{a} *}$, Luis Miguel Sanz-Moral ${ }^{\mathrm{a}}$, Ivan Saldan ${ }^{\mathrm{b}}$, Alessandro Girella ${ }^{\mathrm{c}}$, Chiara Milanese ${ }^{c}$, Ángel Martín ${ }^{a}$

${ }^{a}$ Department of Chemical Engineering and Environmental Technology - University of Valladolid , c/ Doctor Mergelina s/n 47011 Valladolid

${ }^{\mathrm{b}}$ Department of Physical and Colloid Chemistry, Ivan Franko National University of Lviv,6 Kyryla and Mefodia Str., 79005, Lviv, Ukrain

${ }^{\mathrm{c}}$ Pavia $\mathrm{H}_{2}$ Lab, C.S.G.I \& Department of Chemistry, Physical Chemistry Division, Viale Taramelli 16, 27100 University of Pavia (Italy) 


\title{
REVERSIBLE HYDROGEN SORPTION IN THE COMPOSITE MADE OF MAGNESIUM
}

\section{BOROHYDRIDE AND SILICA AEROGEL}

Miriam Rueda $^{\mathrm{a} *}$, Luis Miguel Sanz-Moral ${ }^{\mathrm{a}}$, Ivan Saldan ${ }^{\mathrm{b}}$, Alessandro Girella ${ }^{\mathrm{c}}$, Chiara Milanese $^{c}$, Ángel Martín ${ }^{\text {a }}$

${ }^{\text {a }}$ Department of Chemical Engineering and Environmental Technology - University of c/ Doctor Mergelina s/n 47011 Valladolid

${ }^{\mathrm{b}}$ Department of Physical and Colloid Chemistry, Ivan Franko National University of Lviv,6 Kyryla and Mefodia Str., 79005, Lviv, Ukrain

${ }^{\mathrm{c}}$ Pavia $\mathrm{H}_{2}$ Lab, C.S.G.I \& Department of Chemistry, Physical Chemistry Division, Viale Taramelli 16, 27100 University of Pavia (Italy)

\begin{abstract}
Magnesium borohydride $\mathrm{Mg}\left(\mathrm{BH}_{4}\right)_{2}$ is a promising hydrogen storage material as it releases high hydrogen storage capacity at mild desorption temperatures, but it is still limited by slow hydrogen release kinetics and by the harsh conditions required to re-hydrogenate this compound. In this work, composites made of commercial $\mathrm{Mg}\left(\mathrm{BH}_{4}\right)_{2}$ and synthesized silica aerogel microparticles were prepared by thermal treatment in hydrogen under 120 bar and $200^{\circ} \mathrm{C}$. As a result, the sorption properties of the hydride are improved: calorimetric measurements show that decomposition temperature is reduced by $60^{\circ} \mathrm{C}$, and the typical 3 -step decomposition mechanism of $\mathrm{Mg}\left(\mathrm{BH}_{4}\right)_{2}$ changes to a single-step mechanism in range of 220$400^{\circ} \mathrm{C}$. The kinetics of the first dehydrogenation at $300^{\circ} \mathrm{C}$ was two times faster in $\operatorname{Mg}\left(\mathrm{BH}_{4}\right)_{2}{ }^{-}$ $\mathrm{SiO}_{2}$ composites than in the case of bulk $\gamma-\mathrm{Mg}\left(\mathrm{BH}_{4}\right)_{2}$. Additionally, the re-hydrogenation of this material at comparatively moderate conditions of $390^{\circ} \mathrm{C}$ and 110 bar is presented for the first time, achieving cyclability with a reversible release of hydrogen up to $6 \mathrm{wt} \%$. Different amounts of hydrogen were exchanged depending on the temperature of desorption $\left(300^{\circ} \mathrm{C}\right.$ or $\left.400^{\circ} \mathrm{C}\right)$ and the presence or absence of silica aerogel. This result indicates that silica aerogel chemically interacts with $\mathrm{Mg}\left(\mathrm{BH}_{4}\right)_{2}$, acting as an additive, which can result in different hydrogenationdehydrogenation routes in which different amounts and types of intermediates are formed, influencing the kinetics and the cyclability.

*Corresponding author:

Tel: +34 699142912,

e-mail: miriam.rueda.noriega@gmail.com (M.Rueda)
\end{abstract}


Keywords: hydrogen storage, additive, kinetic, intermediate, reversibility

\section{Introduction}

Hydrogen society, which is related to the use of hydrogen as an energy vector, could be a solution to current environmental and economic problems associated to the use of fossil fuels [1][2]. Due to the low density of hydrogen gas, an important challenge for onboard applications is the search of an effective technology to reversibly store hydrogen in a compact system [3].

Among currently studied solid state hydrogen storage materials, complex metal hydrides, such as $\mathrm{LiBH}_{4}[4]$ or $\mathrm{NaAlH}_{4}$ [5], are very attractive due to their high hydrogen storage capacity, but they are limited by their kinetics and thermodynamics. In this work, magnesium borohydride $\mathrm{Mg}\left(\mathrm{BH}_{4}\right)_{2}$ is also considered as effective storage material due to its high gravimetric $\left(14.8 \%\right.$ wt $\left.\mathrm{H}_{2}\right)$ and volumetric capacity $(0.112 \mathrm{~kg} / \mathrm{L})[6]$, which exceeds the ultimate targets from Department of Energy (DoE) for 2020. Because of these outstanding properties, it could be also of interest in batteries applications, since $\mathrm{Mg}$ metal holds better volumetric capacity and is more abundant than Li. Battery-related applications of this complex hydride has been recently reviewed in [7].

Moreover, $\operatorname{Mg}\left(\mathrm{BH}_{4}\right)_{2}$ starts the decomposition at $270^{\circ} \mathrm{C}$, and although this decomposition temperature still is too high, it is lower than the decomposition temperature of similar alternative compounds. However, due to the formation of stable intermediates [6], rehydrogenation still remains as the main challenge for use of $\mathrm{Mg}\left(\mathrm{BH}_{4}\right)_{2}$ or their composites.

High conditions of pressure and temperature are necessary in order to obtain a high conversion grade for $\mathrm{Mg}\left(\mathrm{BH}_{4}\right)_{2}$ from decomposed products. Reversibility of $11 \mathrm{wt} \%$ of hydrogen [9] was experimentally shown starting from $\mathrm{MgB}_{2}$ to $\mathrm{Mg}\left(\mathrm{BH}_{4}\right)_{2}$ at 950 bar $\mathrm{H}_{2}$ and $400^{\circ} \mathrm{C}$ during 108 hours. In another work of Newhouse et al. [10], $\mathrm{MgB}_{2}$ obtained after thermal decomposition at $600^{\circ} \mathrm{C}$ was partially rehydrogenated, getting $9.7 \mathrm{wt} \%$ of hydrogen by treatment at similar conditions of pressure and temperature $\left(900\right.$ bar $\mathrm{H}_{2}$ and $\left.390^{\circ} \mathrm{C}\right)$ for 3 days. Li et al. [11][12] reported 6.1wt \% hydrogen absorbed after rehydrogenation at $400 \mathrm{bar}_{2}$ and $270^{\circ} \mathrm{C}$ for $48 \mathrm{~h}$ through the formation of the stable $\mathrm{MgB}_{12} \mathrm{H}_{12}$ intermediate. However, when mild pressure and temperature conditions $\left(134\right.$ bar $\mathrm{H}_{2}$ and $\left.\sim 300^{\circ} \mathrm{C}\right)$ were used during rehydrogenation, only 2.7-3.1 $\mathrm{wt} \%$ [6] or 3.5 $\mathrm{wt} \% \mathrm{H}_{2}$ [13] was achieved which most probably corresponded to the formation of $\mathrm{MgH}_{2}$. Also in [14] a triborane $\mathrm{Mg}\left(\mathrm{B}_{3} \mathrm{H}_{8}\right)_{2}$ in addition to $\mathrm{MgH}_{2}$ was experimentally found after dehydrogenation of $\mathrm{Mg}\left(\mathrm{BH}_{4}\right)_{2}$ at $200^{\circ} \mathrm{C}$ for 5 weeks and around $2.5 \mathrm{wt} \% \mathrm{H}_{2}$ was reabsorbed at $250^{\circ} \mathrm{C}$ and 120 bar for 48 hours. In a recent work [15], the rehydrogenation was performed at similar conditions of $280{ }^{\circ} \mathrm{C}$ and 120 bar hydrogen for 
14hours, reabsorbing only $2.5 \mathrm{wt} \%$ suggesting the formation of two $\mathrm{Mg}-\mathrm{B}-\mathrm{H}$ phases during desorption, only one of which being reversible and could explain the limited absorption. The other intermediate compound could be too stable and prevent the complete rehydrogenation.

Different strategies have been tested in order to improve not only the reversibility but also the kinetics and the temperature of the desorption reactions [16] and recently reviewed in [8]. The addition of different additives or catalysts such as $\mathrm{NbF}_{5}, \mathrm{TiO}_{2}, \mathrm{CoCl}_{2}, \mathrm{CoF}_{2}$ or $\mathrm{TiCl}_{3}$ among others [14-15], the confinement in porous materials (mainly in carbon materials) [1921], their combinations [23] or the formation of composites [24] are some of the proposals that have been studied.

Fitchner et el. [20], successfully confined around $44 \mathrm{wt} \%$ of the hydride in activated carbon (BET area of $860 \mathrm{~m}^{2} / \mathrm{g}$ and pore volume of $0.61 \mathrm{~g} / \mathrm{cm}^{3}$ ) using wet impregnation as method and diethyl ether as solvent. As a result, a composite with lower decomposition temperature and lower activation energy was obtained. Wahab et al. [23] infiltrated $45 \mathrm{wt} \% \mathrm{Mg}\left(\mathrm{BH}_{4}\right)_{2}$ in ordered mesoporous carbon CMK-3 scaffold (BET area of $1499 \mathrm{~m}^{2} / \mathrm{g}$ and a volume of pores of $1.63 \mathrm{~cm}^{3} / \mathrm{g}$ ) with addition of $5 \mathrm{wt} \%$ of Ni. In this case, a lowering on $200^{\circ} \mathrm{C}$ in the decomposition temperature was obtained and kinetics of hydrogen release were 10 times faster compared to the bulk $\mathrm{Mg}\left(\mathrm{BH}_{4}\right)_{2}$ due to the synergic effect of nanoconfinement and of the addition of the $\mathrm{Ni}$ catalyst.

Since decomposition tends to occur before melting point, melt infiltration is not a suitable approach for nanoconfinement in this case [19][25]. The only possibility is to confine $\mathrm{MgH}_{2}$ in a support via melt infiltration and then treat the composite with $\mathrm{B}_{2} \mathrm{H}_{6}$ in order to obtain $\mathrm{Mg}\left(\mathrm{BH}_{4}\right)_{2}$ infiltrated in the host [21].

In the case that composites are formed [24], 3.6wt\% of hydrogen was reversible in $1 \mathrm{~h}$ at 90bar hydrogen, after $12 \mathrm{~h}$ of decomposition process at $180{ }^{\circ} \mathrm{C}$ for 20 cycles due to the formation of polyborane intermediates which could transform to $\left[\mathrm{BH}_{4}\right]^{-}$, and make the whole system reversible under mild conditions.

In this work, we report the experimental trial to confine $\operatorname{Mg}\left(\mathrm{BH}_{4}\right)_{2}$ in microparticles of silica aerogel by temperature treatment in hydrogen atmosphere. Microparticles of silica aerogel, which were used for the first time with this complex hydride, have been produced by supercritical $\mathrm{CO}_{2}$ drying, a technique that enables to produce a material with outstanding surface properties. The drying method employed is a key aspect that determines the textural properties of this porous host. If the solvent is removed by evaporation or lyophilization, the capillary stresses associated to the formation of vapor-liquid interfaces inside the pores of the support are responsible of partial collapses of the pore structure of the material. In case of $\mathrm{SiO}_{2}$ matrixes, 
the materials obtained by these drying methods usually show pore volumes below $0.5-1.0$ $\mathrm{cm}^{3} / \mathrm{g}$, such as SBA-15 or MCM-41 mesoporous silica. In contrast, if pressurized or supercritical carbon dioxide is used to extract the solvent, the collapse of the pore structure is avoided or minimized, because under these conditions carbon dioxide is completely miscible with the organic solvent, and therefore the extraction proceeds without formation of gas-liquid interfaces[26] and without capillary stresses, thus resulting in pore volumes up to $4 \mathrm{~cm}^{3} / \mathrm{g}$ [27].

The prepared $\mathrm{Mg}\left(\mathrm{BH}_{4}\right)_{2}-\mathrm{SiO}_{2}$ composites were characterized by SEM, XRD and coupled calorimetric-manometric technics. Their kinetic curves were obtained during several hydrogen desorption-absorption cycles and compared to those of the bulk $\gamma-\mathrm{Mg}\left(\mathrm{BH}_{4}\right)_{2}$.

\section{Experimental methods}

\section{$\underline{2.1 \text { Reactants }}$}

The commercial $\curlyvee-\operatorname{Mg}\left(\mathrm{BH}_{4}\right)_{2}$ powder (Sigma Aldrich, 95\%), thereafter referred to as MBH, was constituted by prismatic particles of around $100 \mu \mathrm{m}$ (see SEM images reported in Section 3).

Tetramethylorthosilicate (TMOS, 98.0\% purity) and ammonium hydroxide $\left(\mathrm{NH}_{4} \mathrm{OH}\right.$, 28.0-30.0\% ammonia) were supplied by Sigma-Aldrich. Methanol $(\mathrm{MeOH} ; 99.8 \%)$ and nhexane $(95 \%)$ were purchased from Panreac. Gaseous Carbon dioxide $\left(\mathrm{CO}_{2}, 99.95 \%\right)$ was supplied by Carburos Metálicos S.A. These reactants are necessary to obtain microparticles of silica aerogel.

Microparticles of silica aerogel were synthesized using a batch supercritical equipment as drying method as reported in a previous work [28]. They were prepared by a sol-gel reaction, using TMOS as precursor and methanol as solvent. While with this procedure it is common to prepare large gel monoliths, in this work the gel was synthetized as microparticles, in order to reduce the possible heat and mass transfer resistances that could be caused by larger aerogel monoliths. To do this, the sol-gel reaction media were dispersed in hexane under mechanical stirring, in order to obtain small droplets of TMOS in methanol dispersed within the hexane continuous phase. After 10 minutes of mechanical stirring of this mixture, an aqueous solution of $\mathrm{NH}_{4} \mathrm{OH}$ was added as condensation catalyst, which induced the gelation of TMOS. The molar ratio used was the following: 1 mol TMOS: 4.4 mol MeOH: $3.3 \mathrm{~mol} \mathrm{H}_{2} \mathrm{O}$ : $4.5 \mathrm{~mol}$ hexane: $0.08 \mathrm{~mol} \mathrm{NH}_{4} \mathrm{OH}$. Gel particles were then kept in a closed vessel immersed in methanol for an aging period for at least 4 days. During this time, the methanol was renewed 2-3 times in order to remove the water content of the solution. After this time, microparticles of alcogel immersed in methanol were dried using supercritical $\mathrm{CO}_{2}$ at 110 bar and $40^{\circ} \mathrm{C}$, employing the supercritical drying apparatus described in a previous work [28]. For this, the system was 
slowly pressurized and depressurized at a rate of $3 \mathrm{bar} / \mathrm{min}$ in order to avoid the cracking of the alcogel/aerogel and mechanical stresses that could damage the structural properties of the final product. Saturated $\mathrm{CO}_{2}$ in the system was renewed four times in order to obtain completely dried particles. Dried silica aerogel microparticles had a porous structure with surface area of $723 \mathrm{~m}^{2} / \mathrm{g}$ and a pore volume of $1.35 \mathrm{~cm}^{3} / \mathrm{g}$ (mean pore size $=7.5 \mathrm{~nm}$ ) [29]. Obtained $\mathrm{SiO}_{2}$ aerogel particles were collected and stored in a closed vial at room temperature until used for MBH$\mathrm{SiO}_{2}$ composite preparation.

\subsection{The $\mathrm{MBH}-\mathrm{SiO}_{2}$ preparation and characterization}

All handling and preparation of the samples took place in a MBRAUN Unilab glove box which continuously purified argon atmosphere where oxygen and moisture values were kept below 1ppm.

Commercial $\gamma-\mathrm{MBH}$ and silica aerogel particles were treated via a pressure-temperature method. First, $\mathrm{SiO}_{2}$ aerogel were heated at $5^{\circ} \mathrm{C} / \mathrm{min}$ in a alumina boat placed in a tubular oven at $110^{\circ} \mathrm{C}$ in the Ar glove-box for 2 hours in order to remove water traces adsorbed by the aerogel from the air. Subsequently, MBH and silica aerogel particles were mixed in a mortar with a mass ratio of 1:1. Around $200 \mathrm{mg}$ of the mixture were introduced in a high pressure stainless steel sample holder under Ar atmosphere in the glove box and then transferred to the Sievert type apparatus (PCT-Pro 2000, Setaram and Hy-Energy), whose experimental set-up is schematically shown in figure 1 . The sample was treated at 120 bar of hydrogen and $200^{\circ} \mathrm{C}$ for 3 hour in order to obtain a composite in which after phase transformation [6] the irreversible $\beta$ phase of $\mathrm{MBH}$, can be coated by $\mathrm{SiO}_{2}$.

\section{(FIGURE 1)}

Kinetic measurements and the study of reversibility were done in the same Sievert type apparatus. The prepared $\mathrm{MBH}-\mathrm{SiO}_{2}$ composite was dehydrogenated and rehydrogenated for 3 cycles in the same high pressure cell. Hydrogen desorption was tested at 300 and $400{ }^{\circ} \mathrm{C}$ both in static vacuum while rehydrogenation was made at $390{ }^{\circ} \mathrm{C}$ under 110 bar $\mathrm{H}_{2}$. The same conditions were used for bulk $\gamma$-MBH in order to compare its reversibility and cyclability with those of the prepared composites.

The gases evolved from the sample during dehydrogenation were analyzed in a residual gas analyzer (RGA Pro, Setaram \& Hy-Energy) connected to the manometric instrument.

Coupled manometric-calorimetric measurements were done by connecting the Sievert apparatus to a high pressure differential scanning calorimeter (DSC, Sensys Setaram) in order to study the influence of silica aerogel in the composite system. The calorimeter cell was loaded with around $19 \mathrm{mg}$ of the sample and heated up to $460^{\circ} \mathrm{C}$ at a rate of $5^{\circ} \mathrm{C} / \mathrm{min}$ in static vacuum. Argon was 
used as carrier gas at $10 \mathrm{~mL} / \mathrm{min}$. Calisto was used as software for data acquisition and processing.

Crystallinity of the different samples was examined using an ex-situ X-ray powder diffractometer (model D5005 Bruker). The measuring conditions were $\mathrm{CuK} \alpha$ radiation, $\lambda=1.54060 \AA, 2 \theta$ angle ranging from $5^{\circ}$ to $90^{\circ}$ with a scan rate of $10 \mathrm{~s} / \mathrm{step}$ and a step size of $0.020^{\circ}$. A Bruker-dome was used in order to avoid the contact with air and perform measurements under Argon (gas in the glove-box) and room temperature.

Particle morphology was observed by Scanning Electron Microscopy (SEM) using EVO-MA10-HR (Zeiss, Germany) with energy-dispersive microprobe analyzer INCA Energy 350X Max from Oxford instruments. A special home-made sample holder was used in order to avoid the contact of the powders with atmospheric oxygen and humidity: in particular, the samples were fixed on $\mathrm{Al}$ stubs by $\mathrm{C}$-tapes in the glove box and closed in the sample holder. Rough vacuum was created in it by a vacuum pump before its extraction from the glove box. Only after reaching high vacuum in the SEM, the sample holder was open and thanks to the 3D movements of the SEM stage and the samples could be analyzed.

\section{Results and discussion}

\section{$\underline{3.1 \mathrm{XRD} \text { and SEM analyses }}$}

$\mathrm{XRD}$ profiles showed that crystalline $\Upsilon$-MBH and amorphous $\mathrm{SiO}_{2}$ (Fig. 2c) were converted into an amorphous mixture after infiltration treatment (Fig. $2 b$ ). The same amorphous spectrum was obtained after several cycles. This fact suggests that in the prepared composites $\mathrm{MBH}$ was amorphous or infiltrated into the pores of $\mathrm{SiO}_{2}$ aerogel.

\section{(FIGURE 2)}

For the hand-made mixture of $\mathrm{MBH}$ and $\mathrm{SiO}_{2}$ aerogel Rietveld refinement was performed similar to the method proposed in [31]. Obtained results suggest that crystalline powder has particle size around $138 \mathrm{~nm}$ and a cell parameter of cubic structure was estimated of $1.5 \mathrm{~nm}$.

In Fig. 3, the SEM image of the prepared $\mathrm{MBH}-\mathrm{SiO}_{2}$ composite is shown. SEM-EDX analysis suggested that $\mathrm{MBH}$ and silica were mixed uniformly and their homogeneity and contact of both components was higher compared to that of their hand-made mixture. At these conditions of pressure and temperature, it was difficult to conclude if $\mathrm{MBH}$ was infiltrated into the pores of the silica aerogel. More pressure would be necessary in order to achieve this, or alternatively another method of infiltration such as wet impregnation should be used. A similar morphology of the composite was observed after $3^{\text {rd }}$ desorption, as it is observed in Fig. $3 b$, which means that silica coating avoided the aggregation of $\mathrm{MBH}$ during the performance of 
cycles. In comparison, the powder of bulk MBH was sintered into a single aggregate after three dehydrogenation-hydrogenation cycles (Fig. 4). In Fig. $4 b$ some single grains of the compacted pellet obtained after cycling were observed. The experimental results suggest that used $\mathrm{SiO}_{2}$ aerogel worked as nanoscaffold avoiding aggregation of $\mathrm{MBH}$ during hydrogen cycling.

(FIGURE 3 AND 4)

\subsection{Coupled calorimetric-manometric measurements.}

DSC results obtained with bulk $\gamma-\mathrm{MBH}$ are shown in Fig. 5 (separately in Fig. S1). Obtained results are in good agreement with those previously reported in [6][13][32][8]. Small temperature differences between the results obtained in this work and literature results can be due to different applied conditions of pressure and heating rate during the measurement [32]. According to Soloveichik et al. [6] , Li et al. [11] and Saldan [8], the first two endothermic peaks $\left(162\right.$ and $194^{\circ} \mathrm{C}$ ) are related to the phase transformation of $\mathrm{MBH}$. Then, in the range of $300-450^{\circ} \mathrm{C}, \mathrm{MBH}$ was decomposed in 3 different steps (D1-D3). During the first two steps ( $\mathrm{T}=307^{\circ} \mathrm{C}$ and $\mathrm{T}=361^{\circ} \mathrm{C}$, respectively), $\mathrm{MBH}$ was decomposed into $\mathrm{MgH}_{2}$ (crystallized during E1) and amorphous boron. After this two-step reaction, $\mathrm{MgH}_{2}$ was decomposed into $\mathrm{Mg}$ in the third step $\left(\mathrm{T}=384^{\circ} \mathrm{C}\right)$ [33][13]. Since $\mathrm{MBH}-\mathrm{SiO}_{2}$ composites preparation was done at $200{ }^{\circ} \mathrm{C}$, the used MBH should be converted to its $\beta$ modification.

Coupled DSC-manometric measurements were carried out for both bulk $\gamma-\mathrm{MBH}$ and the prepared $\mathrm{MBH}-\mathrm{SiO}_{2}$ composite (Fig. 5). Onset of decomposition for the composite was shifted to lower temperature on approximately $60^{\circ} \mathrm{C}$ compare to bulk $\mathrm{MBH}$. A similar result was obtained in a previous work [34], in which $\mathrm{TiO}_{2}$ was used as additive. In this case, the dehydriding temperature was lowered of $50^{\circ} \mathrm{C}$. Therefore, in this work silica could also act as additive improving the breakage of $\mathrm{B}-\mathrm{H}$ bond from $\mathrm{MBH}$ which is the limitation of the decomposition process [21], similarly to those reported in [29].

Moreover, Fig. 5 showed that silica changes the mechanism of the reaction. The three decomposition steps from bulk MBH were converted into only one broad endothermic peak and one higher temperature shoulder of the prepared $\mathrm{MBH}-\mathrm{SiO}_{2}$ composite, a typical behavior of confined hydrides [20]. This fact could be related to the intimal contact between silica and MBH. Similar result was observed in the case of MBH-0.5LiH composite [24], only one broad peak located at $210^{\circ} \mathrm{C}$, involving complicated interactions which may lead to formation of metastable phases. Also in [35] hydrogen was evolved in only one hydrogen step after the formation of $\mathrm{t} \mathrm{MBH}$-ethylendiamine composite.

Since mass of MBH in the prepared composite was 50\%, the final hydrogen release was $\sim 6.6 \mathrm{wt} \% \mathrm{H}_{2}$ that was two times lower than for the bulk MBH (almost $12.0 \mathrm{wt} \% \mathrm{H}_{2}$ ). The small difference in the final amount that is released till $450{ }^{\circ} \mathrm{C}$ could be due to a small instrumental 
error during the preparation of the $\mathrm{MBH}-\mathrm{SiO}_{2}$ sample or surface oxidation of $\mathrm{MBH}$ before the measurement. Otherwise it could be due to an effect of the $\mathrm{SiO}_{2}$ matrix. This would mean that silica not only lowered the decomposition temperature but also its presence makes $\mathrm{MBH}$ to release more hydrogen. As it is known, MBH has a theoretical content of hydrogen of 14.8 $\mathrm{wt} \%$, so higher conditions of temperature $\left(>500^{\circ} \mathrm{C}\right)$ are necessary in order to release all of it.

\section{(FIGURE 5)}

\subsection{Hydrogen desorption at $300^{\circ} \mathrm{C}$ and $400^{\circ} \mathrm{C}$}

Figure 6 shows the kinetics curves of hydrogen desorption for the first desorption cycle at $300^{\circ} \mathrm{C}$ and $400^{\circ} \mathrm{C}$ for bulk $\gamma-\mathrm{MBH}$ and the prepared $\mathrm{MBH}-\mathrm{SiO}_{2}$ composite.

Hydrogen release kinetics at $300^{\circ} \mathrm{C}$ was improved in the sample in which silica was present. Different results were obtained respect to the work of Al-Kukhun et al. [17]. In this work, no changes in hydrogen release kinetics from $\mathrm{MBH}$ at $300^{\circ} \mathrm{C}$ were observed after addition of $\mathrm{SiO}_{2}$. This fact confirmed our SEM observation that a better contact between $\mathrm{MBH}$ and $\mathrm{SiO}_{2}$ was found in the prepared composite, which was not obtained with the simple mixing employed by Al-Kukhun et al. [17], therefore the used aerogel might be considered as nanoscaffold for MBH Alternatively, it could be also due to some different properties of the silica used in this work and in the work of Al-Kukhun et al. [17], such as acidity, which could be responsible of the weakening of B-H bond and the kinetic improvement during dehydrogenation [18].

Regarding the kinetics at the lowest temperature, it took less than 4 hours to complete desorption from $\mathrm{MBH}$ in the composite $\left(\sim 5 \mathrm{wt} \% \mathrm{H}_{2}\right)$, whereas around 8 hours were necessary to release the same normalized amount of hydrogen $\left(\sim 10 \mathrm{wt} \% \mathrm{H}_{2}\right)$ from bulk $\mathrm{MBH}$. This means that dehydrogenation time was reduced by a factor of 2 . Similar results were observed in [10] using $\mathrm{TiF}_{3}$ and $\mathrm{ScCl}_{3}$ as additives ball milled with $\mathrm{MBH}$.

At $400^{\circ} \mathrm{C}$, the release kinetics was similar in both samples. In the case of the composite, the kinetic was shifted to the left because borohydride was decomposed in a shorter time, as observed in the calorimetric measurements discussed in the previous section. Moreover, a different pathway was followed during the dehydrogenation as it was also reported in DSC measurements. Three different steps were distinguished in bulk MBH whereas only one was seen in the prepared composite.

The different mass of hydrogen that was released taking into account that $\mathrm{MBH}: \mathrm{SiO}_{2}$ sample was prepared in a ratio 50:50 can be explained by the same reasons reported in couple DSC-manometric measurements: a different degree of oxidation, or small errors during the preparation of samples. 
(FIGURE 6)

\subsection{Reversible hydrogen sorption}

Figure 7 and 8 show the dehydrogenations at $300^{\circ} \mathrm{C}$ and $400^{\circ} \mathrm{C}$, respectively for several cycles for bulk $\mathrm{MBH}$ and the prepared $\mathrm{MBH}-\mathrm{SiO}_{2}$ composite, performing the rehydrogenation at the same conditions of pressure and temperature of 110 bar and $390^{\circ} \mathrm{C}$.

In the case that desorption was performed at $300^{\circ} \mathrm{C}$ (Fig. 7), both samples were successfully rehydrogenated at milder conditions than those reported in previous works. $3.1 \mathrm{wt} \%$ $\mathrm{H}_{2}$ was released from bulk MBH after rehydrogenation. A similar amount was reported in [6], which could be associated to the rehydrogenation of $\mathrm{MgH}_{2}$, after rehydrogenation of completely decomposed $\mathrm{MBH}\left(\mathrm{MgB}_{2}\right)$. However, in this work products after desorption at $300^{\circ} \mathrm{C}$ (incomplete desorption) were partially rehydrogenated.

In the prepared composite, a lower amount of $\mathrm{H}_{2}$ was released (2.6 wt $\% \mathrm{H}_{2}$ normalized for the amount of $\mathrm{MBH}$ in the sample). This could be due to the formation of more intermediates than in bulk $\mathrm{MBH}$, which were formed during desorption and were more difficult to rehydrogenate, as it was also observed in [10]. Another possibility could be the formation of $\mathrm{B}(\mathrm{OH})_{\mathrm{x}}$ compounds due to the presence of surface hydroxyl groups on silica aerogel particles which might be the reason of the surface deactivation. Thus, the formation of this irreversible compound would explain the lower amount of $\mathrm{H}_{2}$ released in the second cycle in $\mathrm{MBH}-\mathrm{SiO}_{2}$ composite.

Since RGA for the both samples confirmed mainly hydrogen gas (diborane was suppressed), existence of stable solid borane products might be the preliminary problem of reversible hydrogen sorption in MBH. More analyses could be necessary in order to clarify the different dehydrogenation-rehydrogenation mechanism that was followed in each sample.

Regarding the kinetics, it was observed that the second desorption was slower than the first one for both samples. A sluggish kinetic for both samples suggests the existence of a kinetic barrier that suppresses the fast development of the reaction. The addition of a catalyst could be a solution in order to enhance it.

(FIGURE 7)

A different result was obtained in the case that the samples were rehydrogenated after dehydrogenation at $400^{\circ} \mathrm{C}$ (Fig. 8). After 1-st desorption both samples showed $42 \%$ of reversible hydrogen sorption that resulted in $5.4 \mathrm{wt} \% \mathrm{H}_{2}$ for bulk $\mathrm{MBH}$ and $2.9 \mathrm{wt} \% \mathrm{H}_{2}$ for the prepared $\mathrm{MBH}-\mathrm{SiO}_{2}$ composite in practice. 
This is the first time that more than $3 \mathrm{wt} \%$ has been rehydrogenated at moderate

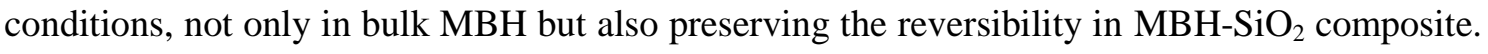
A similar amount was rehydrogenated by $\mathrm{Li}$ et al [11] and [12], but applying a pressure of 400 bar, whereas in this work pressure was reduced to 110 bar. Desorption curves during 2-nd and 3-rd cycles were almost identical for the both sample that suggest a good cyclability. It is visible that complete hydrogen release for both samples was very similar with the only difference of lower kinetics for the composite suggesting activated or deactivated (which is our case) surface of $\mathrm{MBH}$.

After three dehydrogenation-hydrogenation cycles at $400{ }^{\circ} \mathrm{C}$, bulk $\mathrm{MBH}$ powder was sintered and converted into a single compacted pellet with the shape of the reactor used, in contrast to the fine powder morphology that was preserved in the case of the prepared $\mathrm{MBH}-$ $\mathrm{SiO}_{2}$ composite. As it was seen in $\mathrm{SEM}$ analyses, $\mathrm{SiO}_{2}$ avoided the aggregation which could be very disadvantageous for the cyclability of the borohydride.

Most probably partial reversible hydrogen sorption at $400{ }^{\circ} \mathrm{C}$ might be explained by irreversible products formed during dehydrogenation of both bulk $\mathrm{MBH}$ and the prepared $\mathrm{MBH}-\mathrm{SiO}_{2}$ composite.

\section{(FIGURE 8)}

In order to analyze phase composition for the commercial bulk MBH before and after cycling, XRD measurements were performed for $\mathrm{MBH}$ as received and after second dehydrogenation at $400{ }^{\circ} \mathrm{C}$ (Fig. 9). As it was expected, after dehydrogenation diffraction profile revealed the presence of $\mathrm{Mg}(74.9 \%)$ and some $\mathrm{MgO}$ (25.1\%) that could be formed due to the presence of some oxygen during the applied measurement or the presence of nanocrystalline $\mathrm{MgO}$ already in the commercial MBH. In [15], $\mathrm{MgO}$ was also discussed which could form a shell around the reversible $\mathrm{Mg}_{\mathrm{x}} \mathrm{B}_{\mathrm{y}} \mathrm{H}_{\mathrm{z}}$ phases preventing the full rehydrogenation and therefore might be responsible for the reduced reversibility. In the case that some intermediates were present, they would be amorphous as in the case of pure boron. In the prepared $\mathrm{MBH}-\mathrm{SiO}_{2}$ composite, XRD analyses did not reveal any crystalline phase in the spectra after thermal treatment. Some additional methods to analyze amorphous species during dehydrogenationrehydrogenation would be helpful to clarify the difference in the reaction mechanism between bulk $\mathrm{MBH}$ and the prepared $\mathrm{MBH}-\mathrm{SiO}_{2}$ composite.

(FIGURE 9)

\section{Conclusions}

Microparticles of silica aerogel were proposed as host to infiltrate MBH using a thermal treatment in hydrogen at $200^{\circ} \mathrm{C}$ and 120 bar $\mathrm{H}_{2}$ for $3 \mathrm{~h}$. According to the volume of pores of 
microparticles of $\mathrm{SiO}_{2}$ aerogel calculations, it would be possible to infiltrate up to $50 \mathrm{wt} \%$ of $\mathrm{MBH}$.

However, as this method was not satisfactory to confine MBH in the pores of the support, less amount of silica could be used in a future work. As a result, a composite in which silica behaves as additive and a storage material with more total $\mathrm{H}_{2}$ content could be obtained. Wet impregnation is also proposed as future technique to infiltrate $\mathrm{MBH}$ in the pores of silica selecting the correct solvent in order to avoid the decomposition of the hydride.

The temperature of the decomposition of bulk $\mathrm{MBH}$ was decreased almost $60^{\circ} \mathrm{C}$ and the mechanism of the decomposition was changed in the prepared composite. Calorimetric measurements showed that the three steps of decomposition of bulk MBH were converted into only one in range of $240-400^{\circ} \mathrm{C}$. This result indicates an intimal contact between $\mathrm{MBH}$ and silica, which acts as an additive changing the decomposition route, was successfully acquired with this method. Additionally, their kinetics of the first dehydrogenation at $300{ }^{\circ} \mathrm{C}$ was two times faster compared to that of the bulk MBH.

Moreover, for the first time MBH has been demonstrated to be partially reversible at moderate conditions of pressure and temperature $\left(110 \mathrm{bar} \mathrm{H}_{2}\right.$ and $\left.390^{\circ} \mathrm{C}\right)$. Almost $6 \mathrm{wt} \% \mathrm{H}_{2}$ was rehydrogenated when hydrogen desorption was performed at $400^{\circ} \mathrm{C}$.

\section{Acknowledgement}

Authors thank the University of Valladolid fellowship research program FPI-UVa, for the financial support for the stay at the Pavia University. Á. Martín thanks the Spanish Ministry of Economy and Competitiveness for a Ramón y Cajal research fellowship. M. Rueda thanks the University of Valladolid for a FPI predoctoral grant. L. M. Sanz thanks the Spanish Ministry of Economy and Competitiveness for a FPI predoctoral grant. This project has been financed by the Spanish Ministry of Economy and Competitiveness through project ENE2014-53459-R.

\section{References}

[1] Sharma S, Krishna S. Hydrogen the future transportation fuel : From production to applications. Renew Sustain Energy Rev 2015;43:1151-8. doi:10.1016/j.rser.2014.11.093.

[2] Sobrino FH, Monroy CRR, Pérez JLHLH, Perez JLH. Critical analysis on hydrogen as an alternative to fossil fuels and biofuels for vehicles in Europe. Renew Sustain Energy Rev 2010;14:772-80. doi:10.1016/j.rser.2009.10.021.

[3] Balat M. Potential importance of hydrogen as a future solution to environmental and transportation problems. Int J Hydrogen Energy 2008;33:4013-29. doi:10.1016/j.ijhydene.2008.05.047.

[4] Züttel A, Wenger P, Rentsch S, Sudan P, Mauron P, Emmenegger C. LiBH4 a new hydrogen storage material. J Power Sources 2003;118:1-7. doi:10.1016/S0378-7753(03)00054-5.

[5] Bogdanovic, B, Brand, R, Marjanovic, A, Schwickardi, N, Tolle J. Metal-doped sodium aluminium hydrides as potential new hydrogen q storage materials. J Alloys Compd 2000;302:36-58. 
borohydride as a hydrogen storage material : Properties and dehydrogenation pathway of unsolvated $\mathrm{Mg}$ ( BH 4 ) 2. Int J Hydrogen Energy 2009;34:916-28. doi:10.1016/j.ijhydene.2008.11.016.

[7] Zavorotynska O, El-Kharbachi A, Deledda S, Hauback BC. Recent progress in magnesium borohydride $\mathrm{Mg}(\mathrm{BH} 4) 2$ : Fundamentals and applications for energy storage. Int J Hydrogen Energy 2015. doi:10.1016/j.ijhydene.2016.02.015.

[8] Saldan I. Decomposition and formation of magnesium borohydride. Int J Hydrogen Energy 2016;41:1120124. doi:10.1016/j.ijhydene.2016.05.062.

[9] Severa G, Rönnebro E, Jensen CM. Direct hydrogenation of magnesium boride to magnesium borohydride: demonstration of $>11$ weight percent reversible hydrogen storage. Chem Commun (Camb) 2010;46:421-3. doi:10.1039/b921205a.

[10] Newhouse RJ, Stavila V, Hwang SJ, Klebanoff LE, Zhang JZ. Reversibility and improved hydrogen release of magnesium borohydride. J Phys Chem C 2010;114:5224-32. doi:10.1021/jp9116744.

[11] H.W.Li, K.Kikuchi, Y.Nakmori, N.Ohba. M.Miwa, S.Towata SO. Dehydriding and rehydriding processes of well- crystallized $\mathrm{Mg}$ ( $\mathrm{BH} 4$ ) 2 accompanying with formation of intermediate compounds. Acta Mater 2008;56:1342-7. doi:10.1016/j.actamat.2007.11.023.

[12] H.W.Li, Miwa K, Ohba N, Fujita T, Sato T, Yan Y, et al. Formation of an intermediate compound with a B12H12 cluster: experimental and theoretical studies on magnesium borohydride $\mathrm{Mg}(\mathrm{BH} 4) 2$. Nanotechnology 2009;20:204013. doi:10.1088/0957-4484/20/20/204013.

[13] Chłopek K, Frommen C, Léon A, Zabara O, Fichtner M. Synthesis and properties of magnesium tetrahydroborate, $\operatorname{Mg}(\mathrm{BH} 4) 2$. J Mater Chem 2007;17:3496. doi:10.1039/b702723k.

[14] Chong M, Karkamkar A, Autrey T, Orimo S, Jalisatgi S, Jensen CM. Reversible dehydrogenation of magnesium borohydride to magnesium triborane in the solid state under moderate conditions. Chem Commun (Camb) 2011;47:1330-2. doi:10.1039/c0cc03461d.

[15] Zavorotynska O, Deledda S, Hauback BC. Kinetics studies of the reversible partial decomposition reaction in $\mathrm{Mg}(\mathrm{BH} 4) 2$. Int J Hydrogen Energy 2016;41:9885-92. doi:10.1016/j.ijhydene.2016.02.153.

[16] Li H, Yan Y, Orimo S, Züttel A, Jensen CM. Recent Progress in Metal Borohydrides for Hydrogen Storage. Energies 2011;4:185-214. doi:10.3390/en4010185.

[17] Al-Kukhun A, Hwang HT, Varma A. NbF 5 additive improves hydrogen release from magnesium borohydride. Int J Hydrogen Energy 2012;37:17671-7. doi:10.1016/j.ijhydene.2012.09.097.

[18] Paduani C, Jena P. Role of Ti-based catalysts in the dehydrogenation mechanism of magnesium borohydride: A cluster approach. Int J Hydrogen Energy 2013;38:2357-62. doi:10.1016/j.ijhydene.2012.11.060.

[19] Au YS, Yan Y, de Jong KP, Remhof A, de Jongh PE. Pore Confined Synthesis of Magnesium Boron Hydride Nanoparticles. J Phys Chem C 2014;118:20832-9. doi:10.1021/jp507568p.

[20] Fichtner M, Zhao-Karger Z, Hu J, Roth A, Weidler P. The kinetic properties of $\mathrm{Mg}(\mathrm{BH} 4) 2$ infiltrated in activated carbon. Nanotechnology 2009;20:204029. doi:10.1088/0957-4484/20/20/204029.

[21] Yan Y, Au YS, Rentsch D, Remhof A, de Jongh PE, Züttel A. Reversible hydrogen storage in $\mathrm{Mg}(\mathrm{BH} 4) 2 /$ carbon nanocomposites. J Mater Chem A 2013;1:11177. doi:10.1039/c3ta12222k.

[22] Capurso G, Agresti F, Crociani L, Rossetto G, Schiavo B, Maddalena A, et al. Nanoconfined mixed Li and Mg borohydrides as materials for solid state hydrogen storage. Int J Hydrogen Energy 2012;37:768-73. doi:10.1016/j.ijhydene.2012.04.111.

[23] Wahab MA, Jia Y (Alec), Yang D, Zhao H, Yao X. Enhanced hydrogen desorption from Mg(BH4)2 by combining nanoconfinement and a Ni catalyst. J Mater Chem A 2013;1:3471. doi:10.1039/c2ta00899h.

[24] Yang J, Fu H, Song P, Zheng J, Li X. Reversible dehydrogenation of Mg(BH4)2-LiH composite under moderate conditions. Int J Hydrogen Energy 2012;37:6776-83. doi:10.1016/j.ijhydene.2012.01.109.

[25] Paskevicius M, Pitt MP, Webb CJ, Sheppard D a., Filsø U, Gray EM, et al. In-Situ X-ray Diffraction Study of $\gamma-\mathrm{Mg}(\mathrm{BH} 4) 2$ Decomposition. J Phys Chem C 2012;116:15231-40. doi:10.1021/jp302898k.

[26] Sanz-Moral LM, Rueda M, Mato R, Martín Á. View cell investigation of silica aerogels during supercritical drying: Analysis of size variation and mass transfer mechanisms. J Supercrit Fluids 2014;92:24-30. doi:10.1016/j.supflu.2014.05.004. 
[27] Soleimani Dorcheh A, Abbasi MH. Silica aerogel; synthesis, properties and characterization. J Mater Process Technol 2008;199:10-26. doi:10.1016/j.jmatprotec.2007.10.060.

[28] Rueda M, Sanz-Moral LM, Nieto-Márquez A, Longone P, Mattea F, Martín Á. Production of silica aerogel microparticles loaded with ammonia borane by batch and semicontinuous supercritical drying techniques. J Supercrit Fluids 2014;92:299-310. doi:10.1016/j.supflu.2014.06.012.

[29] Rueda, Miriam, Sanz-Moral, LM, Segovia JJ, Martín A. Improvement of the kinetics of hydrogen release from ammonia borane confined in silica aerogel n.d.

[30] Filinchuk Y, Cerny R, Hagemann H. Insight into Mg (BH4) 2 with synchrotron X-ray diffraction: structure revision, crystal chemistry, and anomalous thermal expansion. Chem Mater 2009:925-33. doi:10.1021/cm803019e.

[31] Zavorotynska O, Deledda S, Vitillo J, Saldan I, Guzik M, Baricco M, et al. Combined X-ray and Raman Studies on the Effect of Cobalt Additives on the Decomposition of Magnesium Borohydride. Energies 2015;8:9173-90. doi:10.3390/en8099173.

[32] Hanada N, Chłopek K, Frommen C, Lohstroh W, Fichtner M. Thermal decomposition of Mg(BH4)2 under He flow and H2 pressure. J Mater Chem 2008;18:2611. doi:10.1039/b801049h.

[33] Matsunaga T, Buchter F, Mauron P, Bielman M, Nakamori Y, Orimo S, et al. Hydrogen storage properties of $\mathrm{Mg}[\mathrm{BH} 4] 2$. J Alloys Compd 2008;459:583-8. doi:10.1016/j.jallcom.2007.05.054.

[34] Li H-W, Kikuchi K, Nakamori Y, Miwa K, Towata S, Orimo S. Effects of ball milling and additives on dehydriding behaviors of well-crystallized $\mathrm{Mg}(\mathrm{BH} 4) 2$. Scr Mater 2007;57:679-82. doi:10.1016/j.scriptamat.2007.06.052.

[35] Chen J, Chua YS, Wu H, Xiong Z, He T, Zhou W, et al. Synthesis, structures and dehydrogenation of magnesium borohydride-ethylenediamine composites. Int J Hydrogen Energy 2015;40:412-9. doi:10.1016/j.ijhydene.2014.11.020. 